https://helda.helsinki.fi

\title{
Harry Collins and the Crisis of Expertise
}

\section{Ylikoski, Petri Kullervo}

2016

Ylikoski , P K 2016 , ' Harry Collins and the Crisis of Expertise ', Science \& Education , vol.

pÿ25 , no. 3-4 , 10.1007/s11191-016-9809-7 , pp. 461464 . https://doi.org/10.1007/s11191-016-9809-7

http://hdl.handle.net/10138/233987

https://doi.org/10.1007/s11191-016-9809-7

acceptedVersion

Downloaded from Helda, University of Helsinki institutional repository.

This is an electronic reprint of the original article.

This reprint may differ from the original in pagination and typographic detail.

Please cite the original version. 


\section{Harry Collins and the crisis of expertise}

\section{Harry Collins (2014) Are we all scientific experts now? Polity Press. Cambridge. ISBN-978-0- 7456-8204-4, 144 pages, $€ 12,50$, paperback.}

Reviewed by: Petri Ylikoski, The Institute for Analytical Sociology, Linköping University. Sweden, email: petri.ylikoski@liu.se

This small book presents a compact summary of Harry Collins' current account of expertise and a spirited defense of the epistemic authority of science. A polemical pamphlet like this is naturally short on detailed argumentation, so a review of it has to focus on the big picture.

The central question of the book is: do scientists have any kind of special epistemic authority or expertise? Using his own concepts, Collins asks: is there anything else than default expertise? By default expertise Collins refers to the idea that we are all experts and nobody has any special expertise. If default expertise is all there is, then celebrities and basically anyone able to use the Internet has the same claim to expertise as scientists with special education and research experience on the topic. Collins does not think this is the case, and he suggests that his theory can explain what is the difference between scientific expertise and everyday ability to form opinions about any issue.

Collins begins his argument by presenting a highly streamlined history of science studies in the last century. The basic narrative of chapter 1 is familiar from his other publications. History, philosophy, and sociology of science started as a Wave 1 that accepted the special epistemic status of science, assumed that ultimately scientific knowledge is valid because it corresponds to reality, and thus did not analyze scientific research as ordinary cognitive and social activity. Then came Thomas Kuhn's The Structure of Scientific Revolutions and initiated Wave 2. The sociology of scientific knowledge (SSK) was born. Armed with the principle of symmetry, it opened the black box of epistemic activities in science and demonstrated that they are analyzable in social terms. However, something went wrong. The early SSK studies were hard and painstaking as the sociologists thought it was necessary to understand the science they were studying, but somehow the field was taken over by people whose background was in fields like literary criticism and semiotics and who did not pay attention to the contents of the sciences they studied.

One of the key failures was the acceptance of what Collins calls the relational theory of expertise. According to this view, to be an expert is to be called an expert. This labeling view of expertise led to problems when sociologists analyzed sheep farmers and AIDS activists. As these people seemed to have some relevant expertise and as their expertise was not recognized by the scientific community, they were called lay experts. For Collins this was a fundamental mistake. If we assume that both lay people and scientists are experts, then everybody is an expert and thus we are led to a position that assumes that there is only default expertise. According to Collins, to avoid this conclusion we have to have a substantial theory of expertise. Thus, he argues that the farmers were not lay people but members of an elite group of experienced farmers. The scientific community does not have monopoly on expertise, but this does not imply that everybody is an expert on everything. So in these controversies “... there were still no 'lay experts' involved: members of the general public were nowhere to be seen, except in the distorted interpretations of research." (p. 41) 
In chapter 2 Collins presents a summary of his taxonomy of expertise that focuses on substantive expertise and not merely on the social status of being expert. The first element in the taxonomy is ubiquitous expertise. Ubiquitous expertises are acquired through growing up in a society, and basically everyone has them. Ability to speak one's native language, follow societal mores and norms are examples of this sort of expertise. Everybody has ubiquitous expertise, but it might be very difficult to teach this kind of expertise to a computer. Because this sort of expertise is so widely distributed, it is not usually regarded as expertise. So although ubiquitous expertises are the basis for acquiring any other kind of expertise, they are often invisible.

The route to acquire specialist expertise is to work with other experts and slowly accumulate relevant tacit knowledge. Collins distinguishes two components in specialist expertise. The first is contributory expertise, which is based on the ability to contribute to a field of expertise. The other component is interactional expertise, that is, fluency to talk about the area of expertise. Both of these are lacking in non-experts, who have not been embedded in relevant specialist communities. So no matter how much they have been reading beer mats, popular science, or even specialist publications, they do not have specialist expertise. In other words, reading is not enough for expertise, as one needs a long period of apprentice.

Finally, Collins defines meta-expertise as an ability to judge other experts. Non-transmuted meta-expertise can be based on expertise on related technical domain (referred expertise), one's own competence in the same domain (downward expertise), or technical connoisseurship, which is based on long-term familiarity with the domain. In addition to the specialist meta-expertise, there is also ubiquitous meta-expertise that is based on local or more general discriminative ability to form opinions about expert's competence. Again, this kind of meta-expertise is not a very good basis for evaluating the competence of real experts.

This scheme is put in action in chapters 3 and 4. In chapter 3, Collins argues that evaluation of scientific claims is impossible without being a member of the core-set of specialists who do the experiments, build the theories, and meet each other in conferences. All others are bound to lose nuances and doubts, and thus are victims of the "direct square law" of knowledge: distance lends enchantment. Thus outside readers of the Climategate emails will misunderstand their meaning, non-specialists do not understand why members of gravitation-wave community are fully justified in ignoring Joe Weber's 1996 paper in Il Nuevo Cimento, and how president Mbeki was wrong to interpret scientific literature without expert help when he doubted the safety of anti-retroviral drugs. What is common to all these cases is that non-specialists lack the appropriate interactional and meta-expertise that is necessary to avoid taking incompetent or dishonest views as legitimate scientific positions. Chapter 4 continues the same line of argument by focusing on vaccine protestors. Collins argues that the debate about MMR (Measles, Mumps, and Rubella) vaccine and autism is a case of a counterfeit scientific controversy, which reflects newspapers' failure to do their work properly. While ordinary citizens may be in principle able to recognize distortions of the scientific process, their limited meta-expertise fails when the media's misplaced "balanced" reporting sends them on the wrong track.

In the final chapter Collins summarizes his argument and presents a surprise. When articulating what Wave 3 of science studies would look like, he returns to old Mertonian ideas. He argues that scientific specialists are a special group of people because of their special kind of internalized ethos. If one sets aside fraudsters, muscular capitalists, speculative theoreticians, wild-eyed Darwinians, media scientists, lobbying scientists, and just "intellectually inbred", scientists are basically driven 
to find out the truth. Thus, "... integrity is built into the very nature of science and the relatively rare cheats have simply made a mistake and sacrificed their scientific birthright." (p. 127). This is basically a very simplified version of the Mertonian position. However, Collins goes further. While Merton believed that the norms described by him are justified by their effectiveness in creation of reliable knowledge, Collins states that "... the norms are good in themselves - good in a moral sense.” (p. 128). I guess it is no longer possible to suspect that Collins is some kind of antiscientific relativist.

I believe that the above provides a fair summary of the arguments presented in the book. What do I make of it? First, given the nature of this small book, Collins spends all too much time describing developments inside STS. His idea is to use academic debate as an indicator of broader changes in society, but it would have been better to describe those changes directly. Now we have a highly simplified and polemical account of developments inside one social scientific field, but no analysis of the changes that they are supposed to reflect. The other structural problem is that all the controversies that Collins analyzes are cases of what he calls counterfeit scientific controversies. My point is that it is not much of a challenge to show that Jenny McCarthy is not an expert on scientific issues related to vaccination. It would have been much more interesting to see if Collins' scheme could help in analyzing some real science-related controversies. What to think about those cases where the identification of the core-set is more difficult than in the gravitational wave case? What about those cases where the core-set consists of experts from multiple fields, or where political and economics stakes make the debate more complicated? My point is that one does not need any sociological theory of expertise to reach a right conclusion about the McCarthy case, but it might be very useful in more complicated cases. Based on this book, it is impossible to say whether Collins' theory is helpful in these more demanding cases.

What about the theory itself? Collins' ideas about tacit knowledge and the core-set are familiar to everybody who has read some of his earlier work. Without doubt they capture many important issues related to expertise. However, sometimes Collins seems to stretch these ideas too far in a direction that mystifies expertise. For example, Collins is eager to show that it is completely legitimate for gravitation-wave scientists to completely ignore Joe Weber's 1996 paper. Now, it is completely understandable that these scientists did not have time to read Weber's piece, not to mention writing a rebuttal, but is this really an example of science at its best? Is Collins right in suggesting that outsiders should just trust the specialists' judgment of the paper, although none of them has read it? I think Collins seriously underestimates the role that public argumentation in the front of the broader scientific community plays in science. This is also shown in the comments he makes about Mike Hulme's and Jerry Ravetz's call for openness in climate science. Collins suggests that this call is misguided and argues that it is impossible for scientists to show their working and for science to be publicly owned. However, Hulme and Ravetz are not suggesting that climate science is to be judged by default expertise. Rather, they are calling for openness and assessment state of knowledge by a broader scientific community that goes beyond the core-set of climate scientists. This does not mean the nullification of the expertise of the core-set, it just means implementing the ideals that Merton's norms describe. It might be that Collins does not really mean it, but in these passages he seems to make scientific knowledge more opaque than it needs to be.

My second problem with the theory is the return of the moral character of scientists as the central explanation of the epistemic authority of science. Collins seems to make the moral integrity and good intentions of individual scientists the most crucial explanatory factor. It would be wrong to 
say that this is returning to Merton's ideas. Merton was talking about how institutional practices and norms make science special in terms of producing reliable knowledge. Collins' theory is much more individualistic, and quite clearly less sociological. He is not really returning to Wave 1 ideas, he is returning to ideas that predate Wave 1. And if the central challenge for Wave 3 social studies of science is "to treat science as special without telling fairy stories about it" (p. 81), one can ask how successful Collins' analysis of scientific expertise really is. I am not raising this question as someone who doubts the relevance of ethos in understanding science, I am just puzzled by how simplistic the theory is. Surely there has to be more than morally exemplary individuals.

As a conclusion, I have to report a disappointment about this pamphlet. The topic is important, and based on his earlier work I expected that Harry Collins would have something interesting to say about it. However, it turns out that his main task is to show that a sociologist can justify the intuitive claim that Jenny McCarthy is not a scientific expert. While there might be some internal STS debates where this might be an interesting, or even a radical, idea, for a broader (academic and non-academic) public it does not provide much. The book is less than it could be, and for this reason it is also of limited value in science education. I would prefer my students reading some Collins' papers rather than this book. 